\title{
Measuring the Efficiency of Public Universities: Using Data Envelopment Analysis (DEA) to Examine Public Universities in Saudi Arabia
}

\author{
Fahad Mohammed Alabdulmenem ${ }^{1}$ \\ ${ }^{1}$ Education and Psychology Department, Science and Human Studies College, at Huraimila, Shaqra University, \\ Saudi Arabia \\ Correspondence: Fahad Mohammed Alabdulmenem, Education and Psychology Department, Science and \\ Human Studies College, at Huraimila, Shaqra University, Saudi Arabia. E-mail: morganiteinstitute@yahoo.com
}

Received: April 22, 2016

doi:10.5539/ies.v10n1p137
Accepted: November 18, $2016 \quad$ Online Published: December 24, 2016

URL: http://dx.doi.org/10.5539/ies.v10n1p137

\begin{abstract}
Saudi Arabia is one of the countries that allot substantial amount of government resources for education. Thus, it is important to measure how these resources are used to generate favorable academic outcomes for its nationals. In this study, data envelopment analysis (DEA) is used to measure the relative efficiency of 25 public universities in Saudi Arabia. Results show that although most public universities in the country are efficient, some fall behind in performance due to poor utilization of available resources. Implications of this are discussed and recommendations are provided.
\end{abstract}

Keywords: public universities, Saudi Arabia, measuring, efficiency, data envelopment analysis

\section{Introduction}

It is believed that a country's robust higher education system has positive effects not only on its citizens but also on its economic growth and development. Within the context of globalization, institutions of higher learning are caught under pressure to produce competent graduates who can keep up with the demands of a highly advanced market economy. Supporting this argument, Teichler (2007) states that higher education increases the involvement of individuals in directly contributing to the economic wellbeing of society. Furthermore, he claims that higher education increases the likelihood for enhanced economic activities to take place as the skills and competencies that people develop bring in more opportunities for trade and income generation.

Such responsibility enlarges the demand for colleges, universities, and other higher education institutions to provide high quality educational programs and employ efficient governance systems. While quality of educational programs may be measured against industry and professional standards, efficiency of college or university governance systems may be assessed through their use of available financial, human, and other resources to generate academic-related work outputs such as: number of graduates, number of research publications, academic performance of students, among others. Thus, while program quality is controlled by external factors (professional organizations and/or standards making bodies), efficiency of universities primarily hinges on university policies and processes that are heavily dependent on their governing body or administration.

There is a difference, however, between the governance of public and private universities. While the Ministry of Education regulates both types of higher education institutions, public universities exercise less autonomy compared to private universities in policy development and implementation, especially in terms of identifying priority programs and allocating funds. Provided that public university education is a means for social service delivery of the government, they are mandated to comply with processes and mechanisms required from all government-owned and managed organizations. This reality provides another dimension that should be considered in examining the extent to which public universities are efficient.

\subsection{Purpose of the Study}

It is the goal of the present study to measure the efficiency of Saudi Arabian public universities relative to one another. In doing so, data envelopment analysis (DEA) is used as the framework to identify. 


\subsection{Questions of the Study}

1) Which of the public universities in Saudi Arabia are able to maximize the use of their resources in producing academic output?

2) Which of the public universities in Saudi Arabia need to improve on their current programs, policies, and strategies to increase their outputs?

\section{Review of Related Literature}

This review of related literature has the following objectives: (1) present an overview of how universities in Saudi Arabia are governed and regulated, with emphasis on public universities; (2) to discuss current issues faced by public universities in Saudi Arabia; and (3) to explain how measuring efficiency may address some of these issues faced by higher education institutions in Saudi Arabia.

\subsection{The Regulation of University Systems in Saudi Arabia}

At present, there are 25 public universities and 9 private universities in Saudi Arabia. Two government offices govern these institutions, namely: The Ministry of Higher Education and the Higher Education Council. The Ministry of Higher Education was founded in 1975 to ensure the implementation of higher education policies of the Kingdom, such as teacher training in colleges and girls' colleges (UNESCO, 2011). The Higher Education Council, on the other hand, is responsible for the direct supervision and coordination of higher learning institutions, except for military education. It also ensures that universities, colleges, and other institutions of higher learning are abiding policies and laws concerning higher education and supervises the development of university education in all sectors. Moreover, it serves as a coordinating body of higher learning institutions, encourages scientific research, and establishes key standards in the delivery of higher education to the people of the Kingdom (UNESCO. (2011). Four key principles govern Saudi Arabian public university education, namely: (a) they should be free for all; (b) they should promote equal educational opportunities for students living within and outside the city; (c) they should conduct either all-male or all-female classes only, with the exception of King Abdullah Science University; and (d) their policies, regulations, and curricula should promote the core values of Islam among university students (Elyas \& Picard, 2013). From 2004-2014, the Ministry of Education implemented a Ten-year Strategic Plan (UNESCO, 2011). This plan is seen as a manifestation of the Kingdom's commitment to providing education for the people of the Kingdom at all levels (UNESCO, 2011).

The first public university in in Saudi Arabia was founded in 1957 (Al-Eisa \& Smith, 2013). Since then, the government has been hands on in all matters concerning higher education, most especially in public institutions of higher learning. This includes the number of students to be admitted, the number of faculty and staff, academic policies, staff rules and regulations (Alkhazim, 2003)

There are 3 councils responsible for the governance and administration of each public university in Saudi Arabia, namely: the University Council, the Scientific Council, and the College or Department Councils (Al-Eisa \& Smith, 2013). The University Council serves as the highest decision-making body within the public university system (Al-Eisa \& Smith, 2013). Its roles are administrative by nature such that it formulates academic policies and develops strategic plans for the university. The Minister of Higher Education leads the Council while the university president, vice presidents, and deans serve as members (Al-Eisa \& Smith, 2013). A Higher Education Council representative and three faculty members of the university act as ex officio members (Al-Eisa \& Smith, 2013). This council decides on hiring faculty members, putting up departments or colleges, approving scholarship grants, as well as setting admissions standards (Al-Eisa \& Smith, 2013). Meanwhile, the Scientific Council is primarily responsible for academic activities that the university engages in such as research, fellowships, and other scientific activities (Al-Eisa \& Smith, 2013). The Vice President for Graduate Studies and Research Affairs leads this Council while heads of academic departments or colleges and academic staff are its members. Lastly, the College or Department Councils are concerned with the various academic program offerings of the university. They directly manage and govern students and personnel at their respective college and department levels.

\subsection{Current Issues Faced by Public Universities in Saudi Arabia}

Given that Saudi Arabia is a relatively new country, the natural process of development requires it to undergo changes and adjustments in terms of policies and processes, including those that concern higher education in which public universities are part of. In conducting this literature review, four major issues that need to be addressed emerged. These are: (1) governance and policy reforms; (Alkhazim, 2003). (2) development of higher education programs based on the needs of the present labor market; (3) regulation of international programs; and (4) gender gap in higher education. 
The issue on governance and policy reforms envelops matters regarding access, funding, and quality standards of public universities (Alkhazim, 2003) The emergence of this issue recognizes the fact that there are individuals in Saudi Arabia who live in areas without higher education institutions, that government funds are diminishing and may affect the type and amount of support given to individuals who express interest in seeking higher education, that there is not enough qualified faculty and staff who possess the necessary skills required to teach at university level, and that the Ministry of Higher Education has difficulties in setting higher education standards across different fields of study, in both private and public universities.

Meanwhile, another issue that confronts public universities in Saudi Arabia is the development of higher education programs based on the needs of the present labor market. While it is the Ministry of Higher Education's goal to contribute to their country's economic growth and development, the programs offered at the university level still need further enhancement to reach the country's desired end. According to (Issa \& Siddiek, 2012), there appears to be a disjunction in the programs of higher education institutions, the country's development needs, and the labor market in Saudi Arabia such that relevant work skills and attitudes of university students are underdeveloped by the time they graduate) (Issa \& Siddiek, 2012). Similarly, teachers and professors who have been trained locally are inclined to devote more time to the study of Islam instead of teaching students about recent science and technology-related topics. Provided that today's labor market is highly dependent on computers and information technology, this reality remains to be a challenge, especially in advancing commerce and trade (Issa \& Siddiek, 2012).

Subsequently, regulation of international programs is adds to the list of issues that Saudi Arabia's public institutions of higher learning are faced with. In the 2016 data of Global Flow of Tertiary Level Students published by the UNESCO Institute for Statistics (UIS), Saudi Arabia ranks as the 6th country with the most number of students studying abroad (73,548 students) (Elyas \& Picard, 2013). On one hand, this encourages Saudi nationals to gain new knowledge and perspectives from fellow students and professors in other geographical regions in the world. On the flipside, this raises the awareness of young Saudi professionals about their employment opportunities overseas that makes them reconsider returning to their home country after earning their degrees. If this issue is not addressed, then the number of science, technology, engineering, and mathematics professionals will continue to decline while the government's funds that support international study also diminish.

Lastly, the gender gap in public universities remains to be a challenge. While women in Saudi Arabia are allowed to enroll in public universities of higher learning, they are restrained from taking academic disciplines that are populated by male enrollees (e.g., engineering) (UNESCO Institute for Statistics, 2016). Hamdan (2005) further explains this claim, saying that women are not allowed to enlist in courses that require them to attend classes with men (Mazawi, 1999). Recently, Profanter (2014) directly points out that this gender inequality is caused by the conservatism of the Muslim culture (Hamdan, 2005). As a result, greater financial burden is placed on women who have a higher unemployment rate of $21.7 \%$ compared to a rate of $7.6 \%$ for men (Profanter, 2014).

In sum, the issues faced by public universities in Saudi Arabia are multi-faceted. They require changes in policy, culture, as well as personal perceptions. Various reforms have been made by the government of Saudi Arabia to enhance its higher education system in the recent years. For instance, the "King Abdullah Scholarship Program" was launched in 2005 to address the lack of qualified teachers, professors, and other professionals needed by the market economy of Saudi Arabia (Profanter, 2014) The said scholarship program supports international education of both men and women at the baccalaureate, masters, and doctoral levels across various fields of study (Alamri, 2011). Additionally, the Ministry of Higher Education renewed its commitment to equal educational opportunities by sponsoring less fortunate students to study at local private universities in Saudi Arabia by 2010 (Alamri, 2011). However, monitoring and assessment of these reforms as well as the development of other reforms are still needed to address these issues faced by public universities in the said country. Additionally, measuring the performance of public universities at present is also needed to have an empirical basis for policy reform and development of interventions to improve the public university system in Saudi Arabia.

\subsection{Measuring the Efficiency of Public Universities}

The essential step in measuring efficiency is to compare the amount of resources used to produce a particular $\mathrm{good} / \mathrm{s}$ or service/s and the actual amount of good/s and/or services produced. While this seems to be commonplace in the field of business, the efficiency of public universities has not been studied until the recent decades (i.e., Kabók, Kis, Csüllög, \& Lendák, 2013; Al-Enezi, Burney, Johnes, Al-Musallam, 2010; Afonso \& Santos, 2008; Debnath, Shankar, \& Kumar, 2008; Flegg, Allen, Field, \& Thurlow, 2004; Avkiran, 2001). This 
development has been triggered by the need to keep up with the demands of the globalized market economy for highly skilled individuals who are crucial for innovation, commerce and trade.

Acknowledging this challenge, the government of Saudi Arabia responds by aiming to improve its education sector, including its public university system. In terms of funding, education-related activities were allocated $25 \%$ of total national budget in 2015, amounting to around USD 53 million (Avkiran, 2001) The funds are meant for the construction and renovation of universities, schools, and other infrastructure for the education of children and the youth (Government of the United Kingdom, 2015). However, despite this generous funding from the government, the Saudi Arabian public universities are still facing issues concerning higher education programs and university student outcomes, such as the below-par work skills and attitudes of university graduates (Government of the United Kingdom, 2015), the apparent disconnection between higher education programs that would address the demands of the labor market, and the gender gap in public university education, most especially in STEM university programs.

\subsection{Analytical Framework}

The use of DEA in evaluating the efficiency of educational institutions was a product of the US Department of Education's attempts to assess educational programs for less fortunate students in the 1970s. It was an expanded version of "The Measurement of Productive Efficiency", an article published by M. J. Farrell in the Journal of the Royal Statistical Society (1957) (Cooper, Seiford, \& Tone, 2007).

Developed by Charnes, Cooper, and Rhodes in 1978, DEA is a framework which is used to assess efficiency by comparing the amount of inputs against the outputs of organizations or entities. Over the past decades, this framework for analysis has been used across industries and disciplines with the aim of identifying possible means to optimize performance of various institutions.

In their seminal piece which was published in the European Journal of Operations Research, Charnes, Cooper, and Rhodes (1978) defined DEA as "a non-linear programming model provides a new definition of efficiency for use in evaluating activities of not-for-profit entities participating in public programs" (p. 429). They clearly stated that it is a measure of efficiency where each participating unit in an organization called "decision making units or DMUs" are assigned weights based on information provided by multiple outputs and multiple inputs essential to the operations of the specific entity/ties being evaluated. In DEA, the efficiency of a particular decision making unit (DMU) is computed by comparing the weighted sum of the organization's inputs against the weighted sum of its outputs.

This framework of analysis will be used in the present study by comparing multiple university inputs (i.e., number of faculty, number of students, etc.) against multiple outputs (i.e., number of graduates, number of publications, etc.), the relative efficiency of Saudi Arabian public higher learning institutions. Through this analytical framework, the current study will be able to identify which of the 25 public universities are maximizing the use of their resources provided by the government to generate academic outputs and which of them lag behind in terms of performance. Towards the end of this study, recommendations regarding government policy reform and possible strategies that may be employed by these public higher learning institutions will be provided.

\section{Methodology}

The current study uses a quantitative research design, as necessitated by DEA as the framework for analysis. Data is obtained from public universities' annual statistics which are with the Ministry of Higher Education. The said government ministry makes government university statistics publicly available through its website (http://www.mohe.gov.sa). These data have been collected, organized, and analyzed through the use of Microsoft Office Excel Solver.

\subsection{Sample}

Since there are only 25 public universities in Saudi Arabia, data from all these universities were gathered to carry out the objectives of this study. Specifically, the following universities were included in analyzing the efficiency of public universities: Umm Al-Qura University Islamic University in Madinah, Imam Muhammad Ibn Saud University, King Saud University, King Abdul Aziz University, King Fahd University of Petroleum and Minerals, King Faisal University, King Khalid University, Qassim University, Taibah University, Taif University, King Saud bin Abdulaziz University for Health Sciences, Jizan University, University of Hail, Al Jawf University, Tabuk University, Al Baha University, Najran University, Princess Noura Bint Abdul Rahman University, Northern Border University, Shaqra University, Salman Bin AbdulAziz University, University of Dammam, Al Majma'ah University, and Saudi Electronic University. 


\subsection{Procedures}

After data were collected from the Ministry of Higher Education website, they were organized and clustered based on the input and output variables available to carry out the analysis. Using DEA as the framework of this study, the 25 universities are treated as the decision making units (DMUs), input variables include faculty and administrators while output variables are number of new entrants, number of enrollees, and number of graduates. These were then analyzed using the Microsoft Office Excel Solver Tool which generated the weights of each DMU and their efficiency scores.

Data envelopment analysis, when performed in Excel using the tool/macro Solver, simplifies the mathematical model on the input side by (1) using the function 'SUMPRODUCT' to combine weights and the input values of all the decision-making units (DMU); and (2) the product of the derived efficiency rate and the specific input value of the DMU in consideration. The solver, depicted above, illustrates how the efficiency rating of each public university. Interestingly, fifteen public universities operated at perfect efficiency (1.0) while 10 were not. The results of these analyses are presented in the next section.

\section{Results}

The data from 25 Saudi Arabian universities reveal that 15 of them are operating on perfect efficiency. The main issue to explore, then, is the group of schools running below perfect efficiency. The two highest-ranking schools below perfect efficiency, King Fahd University of Petroleum and Minerals and Taif University, present two examples of inefficiency caused by suboptimal and less productive inputs, respectively. King Fahd University of Petroleum and Minerals had nearly a thousand more administrators than the value that would make it perfectly efficient $(2,003$ against 1,907$)$, while Taif University produced less new entrant associates, current (enrollment) associates, bachelor, and graduate degree-holders despite having the perfectly efficiently number of faculty and administrators. The same observation could be made about the second-worst performing DMU, University of Hail. University of Hail, despite being .37 points less efficient than Taif University, tallies perfectly efficient input values (faculty and administrators), yet has underperforming faculty and administrators due to the low output values relative to the rest of the DMUs that they help produce.

Table 1. Efficiency scores of the 25 Saudi Arabian public universities

\begin{tabular}{ll}
\hline Name of University & Efficiency \\
\hline Umm Al-Qura University & 1.00 \\
Islamic University Madinah & 1.00 \\
Imad Muhammad Ibn Saud University & 1.00 \\
King Saud University & 1.00 \\
King Abdul Aziz University & 1.00 \\
King Faisal University & 1.00 \\
King Khalid University & 1.00 \\
Taibah University & 1.00 \\
King Saud bin Abdulaziz U for Health Sciences & 1.00 \\
Jizan University & 1.00 \\
Tabuk University & 1.00 \\
Najran University & 1.00 \\
Shaqra University & 1.00 \\
Al Majma'ah University & 1.00 \\
Saudi Electronic University & 1.00 \\
King Fahd U of Petroleum \& Minerals & 0.94 \\
Taif University & 0.92 \\
Al Baha University & 0.86 \\
Northern Border University & 0.82 \\
\hline
\end{tabular}




\begin{tabular}{ll}
\hline Al Jawf University & 0.81 \\
Qassim University & 0.79 \\
University of Dammam & 0.68 \\
Princess Noura Bint Abdul Rahman University & 0.60 \\
University of Hail & 0.55 \\
Salman Bin Abdulaziz University & 0.49 \\
\hline
\end{tabular}

This is yet another useful insight DEA helps bring about. Just like in the hypothetical example above, having perfectly efficient inputs does not guarantee perfect efficiency. These inputs may be performing at sub-optimality, which means they generate less output than the values found to be at perfect efficiency.

\subsection{Conclusion and Recommendations}

Two important points about data envelopment analysis (DEA) need to be underscored. First, DEA is used to measure the efficiency of like and comparable decision-making units (DMUs) relative to one another. A perfectly efficient DMU registers a score of 1 , and is perfectly efficient relative to other DMUs it is being compared to. Thus, a perfectly efficient DMU in the context of DEA does not equate to a perfectly efficient DMU in a sample larger or even smaller than it originally was compared to.

Second, DEA helps alleviate the problem of comparing DMUs based on numerous outputs. Hypothetically, comparing two or more DMUs based on one output would lead to a plausible conclusion about which DMU is more efficient. For example, if School A has 50 faculty members who help produce 100 graduates, School B has 60 faculty and 90 graduates, and School $\mathrm{C}$ has 50 faculty and 95 graduates, it is clear that School A is the most efficient of the three DMUs. School A makes use of the least input to produce the most output. However, this is a very simplistic example. The real world is much more complicated, and efficiency of a DMU is measured through many different inputs and outputs. Here lies the value of DEA as it circumvents the problem of lining up multiple inputs and outputs to ascertain efficiency.

Despite not having restrictions or a minimum number of inputs and/or outputs, DEA is a tool that is maximized when as many pertinent inputs and outputs are incorporated into the dataset and calculation. This does not imply that a researcher should simply throw as many variables into a dataset. Rather, DEA welcomes the researcher to conceptualize as multi-dimensional a description of the measure under scrutiny. Applying this to the present research, the evaluation of university efficiency needs to integrate more inputs than faculty and administration. The number of classrooms, Internet or WI-FI access, and average number of office hours a faculty member holds are just some examples of inputs that could contribute to a richer operationalization of university efficiency.

This research also provides insights on the issue of higher education governance and policy reforms in Saudi Arabia. As mentioned above, more inputs should be examined to measure the efficiency of public universities. By conducting DEA on these additional factors that should be considered, specific matters such as access, funding, and quality standards of public universities may be addressed.

That said, this project is a potent exploratory look into the efficiency of Saudi Arabian universities. The use of DEA illustrates how much can be done even with a rather limited set of inputs. Its potential is far-reaching.

\section{References}

Afonso, A., \& Santos, M. (2008). A DEA approach to the relative efficiency of Portuguese public universities. Portuguese Journal of Management Studies, 13(1), 67-88.

Alamri, M. (2011). Higher education in Saudi Arabia. Journal of Higher Education Theory and Practice, 11, 4.

Al-Eisa, E. S., \& Smith, L. (2013). Governance in Saudi higher education. In L. Smith, \& A. Abouammoh (Eds.), Higher education in Saudi Arabia: Achievements, challenges and opportunities (pp. 27-36). Dordrecht: Springer. https://doi.org/10.1007/978-94-007-6321-0_3

Al-Enezi, M., Burney, N., Johnes, J., \& Al-Musallam, M. (2010). An assessment of efficiency of public schools in Kuwait using data envelopment approach (DEA) and to bit regression. Journal of Development and Economic Policies, 12(2), 7-33.

Alkhazim, M. A. (2003). Higher education in Saudi Arabia: Challenges, solutions, and opportunities missed. Higher Education Policy, 16, 479-486. https://doi.org/10.1057/palgrave.hep.8300035 
Avkiran, N. K. (2001). Investigating technical and scale efficiencies of Australian Universities through data envelopment analysis. Socio-Economic Planning Sciences, $35, \quad$ 57-80. https://doi.org/10.1016/S0038-0121(00)00010-0

Bowlin, W. F. (1998). Measuring performance: An introduction to data envelopment analysis (DEA). Journal of Cost Analysis, 7, 3-27. https://doi.org/10.1080/08823871.1998.10462318

Charnes, A., Cooper, W. W., \& Rhodes, E. (1978). Measuring the efficiency of decision making units. European Journal of Operational Research, 2(6), 429-444. https://doi.org/10.1016/0377-2217(78)90138-8

Cooper, W. W., Seiford, L. M., \& Tone, K. (2007). Basic CCR model. In W. W. Cooper, L. M. Seiford, \& K. Tone (Eds.), Data Envelopment Analysis: A Comprehensive Text with Models, Applications, References and DEA-Solver Software (2nd ed., pp. 21-40). New York: Springer.

Debnath, R. M., Shankar, R., \& Kumar, S. (2008). Performance evaluation of technical institutions: An application of data envelopment analysis. Education, Knowledge and Economy, 2(1), 51-66. https://doi.org/10.1080/17496890801961995

Elyas, T., \& Picard, M. (2013). Critiquing of higher education policy in Saudi Arabia: towards a new neoliberalism. Education, Business and Society: Contemporary Middle Eastern Issues, 6, 31-41. https://doi.org/10.1108/17537981311314709

Farrell, M. J. (1957). The measurement of productive efficiency. Journal of the Royal Statistical Society Series A (General), 120(3), 253-290. https://doi.org/10.2307/2343100

Flegg, A. T., Allen, D. O., Field, T., \& Thurlow, T. W. (2004). Measuring the efficiency of British universities: a multi-period data envelopment analysis. Education Economics, 12(3), 231-249. https://doi.org/10.1080/0904529042000258590

Government of the United Kingdom. (2015). Saudi Arabia- Record budget for 2015. Retrieved from https://www.gov.uk/government/publications/saudi-arabia-record-budget-for-2015/saudi-arabia-record-budg et-for-2015

Government of the United Kingdom. (2015). Saudi Arabia-Record budget for 2015. Retrieved from https://www.gov.uk/government/publications/saudi-arabia-record-budget-for-2015/saudi-arabia-record-budg et-for-2015

Hamdan, A. (2005). Women and education in Saudi Arabia: Challenges and achievements. International Education Journal, 6(1), 42-64.

Issa, A. T. E., \& Siddiek, A. G. (2012). Higher education in the Arab world \& challenges of the labor market. International Journal of Business and Social Science, 3(9), 146-151.

Kabók, J., Kis, T., Csüllög, M., \& Lendák, I. (2013). Data Envelopment Analysis of Higher Education Competitiveness Indices in Europe. Acta Polytechnica Hungarica, 10(3), 185-201.

Mazawi, A. E. (1999). Gender and higher education in the Arab states. International Higher Education, 18-19.

Profanter, A. (2014). Achievements and challenges in the educational realm in Saudi Arabia. European Scientific Journal, 1, 207-222.

Teichler, U. (2007). Higher education and the world of work: Conceptual frameworks, comparative perspectives, empirical findings. Rotterdam: Sense Publishers.

UNESCO Institute for Statistics. (2016). Global flow of tertiary-level students. Retrieved from http://www.uis.unesco.org/Education/Pages/international-student-flow-viz.aspx

UNESCO. (2011). World data on education (Vol. 7). Paris, France: UNESCO.

\section{Copyrights}

Copyright for this article is retained by the author(s), with first publication rights granted to the journal.

This is an open-access article distributed under the terms and conditions of the Creative Commons Attribution license (http://creativecommons.org/licenses/by/4.0/). 